\title{
Vapor-Phase Strategy to Pillaring of Two-Dimensional Zeolite
}

Lu Wei ${ }^{1,2}$, Kechen Song ${ }^{2,3}$, Wei Wu ${ }^{2}$, Scott Holdren ${ }^{4}$, Guanghui Zhu ${ }^{5}$, Emily Shulman ${ }^{2}$, Wenjin Shang ${ }^{6}$, Huiyong Chen ${ }^{6}$, Michael R. Zachariah ${ }^{4 \pm}$ and Dongxia Liu ${ }^{2 *}$

1. College of Materials Science and Engineering, Beijing University of Technology, Beijing, 100124, China

2. Department of Chemical and Biomolecular Engineering, University of Maryland, College Park, MD, 20742, USA

3. School of Chemical and Environmental Engineering, China University of Mining and Technology, Beijing, 100083, China

4. Department of Chemistry and Biochemistry, University of Maryland, College Park, MD, 20742, USA

5. School of Chemical and Biomolecular Engineering, Georgia Institute of Technology, Atlanta, 30332, USA

6. School of Chemical Engineering, Northwest University, Xi'an, Shanxi, 710069, China

\pm current address: Department of Chemical and Environmental Engineering, University of California, Riverside mrz@engr.ucr.edu

*Corresponding author:

Prof. Dongxia Liu

Email: liud@umd.edu

Phone: (+1) 301-405-3522

Fax: (+1) 301-405-0523 


\section{S1. Experimental}

\section{S1.1 Materials}

Sodium hydroxide $\left(\mathrm{NaOH}, \geq 97.0 \%\right.$ purity), sulfuric acid $\left(\mathrm{H}_{2} \mathrm{SO}_{4}, 95.0 \%\right)$, and tetraethyl orthosilicate (TEOS, $\mathrm{Si}\left(\mathrm{OC}_{2} \mathrm{H}_{5}\right)_{4}, 98 \%$ purity) were supplied by Alfa Aesar. Aluminum sulfate hydrate $\left(\mathrm{Al}_{2}\left(\mathrm{SO}_{4}\right)_{3} \cdot 16 \mathrm{H}_{2} \mathrm{O}, 98.0-103.0 \%\right)$, benzyl alcohol (99.95\% purity) and mesitylene (99\% purity) were purchased from Sigma-Aldrich. Deionized (DI) water was used throughout the synthesis. Diquaternary ammonium surfactant $\left(\left[\mathrm{C}_{22} \mathrm{H}_{45}-\mathrm{N}^{+}\left(\mathrm{CH}_{3}\right)_{2}-\mathrm{C}_{6} \mathrm{H}_{12}-\right.\right.$ $\left.\left.\mathrm{N}^{+}\left(\mathrm{CH}_{3}\right)_{2}-\mathrm{C}_{6} \mathrm{H}_{13}\right] \mathrm{Br}_{2},\left(\mathrm{C}_{22-6-6}\right)\right)$ was synthesized following the procedure reported by Ryoo et $\mathrm{al}^{1}$. We have explained the procedure in our previous publications ${ }^{2,3}$. The conventional MFI zeolite was purchased from Zeolyst $(\mathrm{Si} / \mathrm{Al}=80, \mathrm{CBV} 8014)$ in the $\mathrm{NH}_{4}{ }^{+}$-form.

\section{S1.2 Synthesis of multilamellar MFI (M-MFI(P) and M-MFI) zeolites}

The pillared MFI (PMFI) zeolite was synthesized from the multilamellar MFI that was used as the precursor of PMFI (denoted as M-MFI (P)). The synthesis of M-MFI(P) was conducted following the reported method ${ }^{1}$. In a typical synthesis, a basic solution was obtained by dissolving $0.7 \mathrm{~g} \mathrm{NaOH}$ in $3.1 \mathrm{~g}$ DI water. The basic solution was added dropwise to an acidic solution that was prepared by dissolving $0.4 \mathrm{~g} \mathrm{H}_{2} \mathrm{SO}_{4}$ in $4.2 \mathrm{~g}$ DI water under vigorous stirring. After cooling the mixed solution to room temperature, $0.2 \mathrm{~g} \mathrm{Al}_{2}(\mathrm{SO})_{4} \cdot 16 \mathrm{H}_{2} \mathrm{O}$ was dissolved in the solution under sonication. Then, $6.3 \mathrm{~g}$ TEOS were added and the mixture was stirred magnetically at ambient temperature for $20 \mathrm{~h}$. Finally, the $\mathrm{C}_{22-6-6}$ solution that was prepared by dissolving $2.2 \mathrm{~g} \mathrm{C}_{22-6-6}$ in $15.0 \mathrm{~g}$ DI water at $333 \mathrm{~K}$ was added. The resultant mixture was stirred for $2 \mathrm{~h}$ before it was transferred into a $45 \mathrm{~mL}$ Teflon-lined stainless steel autoclave. The autoclave was kept at $423 \mathrm{~K}$ in a convective oven (Yamato DKN400) for 5 days under tumbling at a speed of $40 \mathrm{rpm}$ to hydrothermally synthesize M-MFI(P). The zeolite product was collected by centrifugation, washed with DI water to reduce the $\mathrm{pH}$ to $\sim 9$, and dried in the convective oven at $343 \mathrm{~K}$ for $12 \mathrm{~h}$. Afterwards, a portion of the M-MFI(P) sample was calcined at $723 \mathrm{~K}$

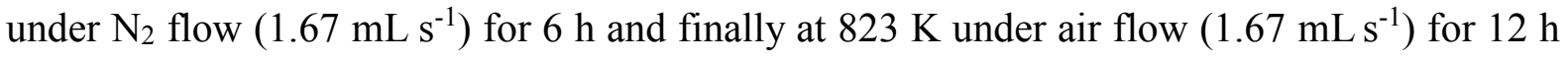
(temperature ramp rate of $0.033 \mathrm{~K} \mathrm{~s}^{-1}$ ) in a furnace (Linderberg Blu M, BF51866A-1) to produce M-MFI zeolite. The rest of the M-MFI(P) sample was used for synthesis of PMFI in the VPP process described below.

\section{S1.3 Synthesis of PMFI zeolite}

Two VPP processes were developed to synthesize PMFI zeolites: the first one used two apparatuses (autoclave and furnace) and discrete operation for three steps (TEOS intercalation, TEOS hydrolysis and calcination) (Figure 1), and the second one only used one apparatus (furnace) and one-time continuous operation for three synthesis steps (Figure 3 ). In the first VPP process, $0.1 \mathrm{~g} \mathrm{M-MFI(P)} \mathrm{sample} \mathrm{was} \mathrm{placed} \mathrm{in} \mathrm{a} \mathrm{glass} \mathrm{vial}(5 \mathrm{~mL})$, and then kept in a Teflon cup $(50 \mathrm{~mL})$ enclosed in the stainless-steel autoclave. $0.05 \mathrm{~g}$ TEOS was added into the Teflon cup and stayed outside of the glass vial. The autoclave was then placed in a convective oven that was preheated to $423 \mathrm{~K}$ for $24 \mathrm{~h}$. In the next step, the autoclave was cooled down to ambient temperature in the fume hood, and the glass vial containing the zeolite sample was moved into a new autoclave that contained $1.0 \mathrm{~g}$ DI water in the Teflon cup. After heating the autoclave in the same oven at $353 \mathrm{~K}$ for $24 \mathrm{~h}$, the zeolite sample was transferred into a crucible 
in the furnace (Linderberg Blu M, BF51866A-1). Finally, the sample was calcined following the same procedure as that of M-MFI synthesis in Section 1.2 to form PMFI zeolite.

For the second VPP process for synthesis of PMFI, the "U"-shaped quartz reactor was used as a container for holding the zeolite sample. The outer diameter of quartz tube is $1 / 4$ " and the "bulb" region is $1 / 2$ " in the reactor. Typically, $0.1 \mathrm{~g} \mathrm{M-MFI(P)} \mathrm{sample} \mathrm{was} \mathrm{loaded} \mathrm{into}$ one side of the " $U$ "-shape reactor, and $0.05 \mathrm{~g}$ TEOS was dropped into the reactor from the other side. A quartz frit separated the zeolite sample from direct contact with TEOS liquid in the reactor. The reactor was then placed into the furnace and connected in the gas flow lines according to the schematics in Figure 3. After running the furnace according to the temperature profile and gas flows in Figure 3, the reactor was cooled down to ambient temperature and PMFI was taken out for physiochemical property characterizations.

\section{S1.4 Material characterization}

X-ray diffraction (XRD) analysis was done on a Rigaku Rotaflex Diffractometer using $\mathrm{Cu} \mathrm{K} \alpha$ radiation $(\lambda=1.5418 \AA)$. $\mathrm{N}_{2}$ adsorption-desorption isotherm was measured on an Autosorb-iQ analyzer (Quantachrome Instruments) at $87 \mathrm{~K}$. The sample was degassed for $12 \mathrm{~h}$ at $573 \mathrm{~K}$ before the isotherm measurement. Scanning electron microscopy (SEM) was performed with Hitachi Model SU-70. Transmission electron microscopy (TEM) was obtained using a JEM 2100 LaB6 electron microscope operating at $200 \mathrm{kV}$. Fourier transform infrared (FTIR) spectra of zeolite and pyridine adsorbed on zeolite samples were recorded using a (FTIR) spectrometer (Nicolet Magna-IR 560) with a resolution of $2 \mathrm{~cm}^{-1}$. Elemental composition of the zeolite samples was determined by inductively coupled plasma optical emission spectroscopy (ICP-OES, PerkinElmer, Optima 7000DV). Solid-state magic-angle spinning (MAS) nuclear magnetic resonance (NMR) spectra were recorded on a Bruker Avance AV 500. ${ }^{29}$ Si MAS NMR spectra were recorded at $99.37 \mathrm{MHz}$ using $4 \mathrm{~mm}$ rotors at a spinning speed of $8 \mathrm{kHz}$, a dwell time of $16.65 \mu \mathrm{s}$, a $\pi / 2$ pulse of $4.0 \mu \mathrm{s}$ and a recycle delay of $60 \mathrm{~s}$. The spectra were referenced with respect to 3 -(trimethysilyl)-1-propanesulfonic acid salt. ${ }^{27} \mathrm{Al}$ MAS NMR spectra were recorded at $130.34 \mathrm{MHz}$ using $4 \mathrm{~mm}$ rotors at $14 \mathrm{kHz}$ spinning speed, a dwell time of $0.5 \mu \mathrm{s}$, a selective $\pi / 18$ pulse of $0.3 \mu \mathrm{s}$ and a recycle delay of $0.1 \mathrm{~s}$. An aqueous solution of $\mathrm{Al}_{2}\left(\mathrm{SO}_{4}\right)_{3}(0.1 \mathrm{M})$ was used as reference. The amount of water and organics in the zeolite samples was measured using a thermo-gravimetric analyzer (TGA) (Shimadzu, TGA50). In the TGA measurement, the temperature was increased to $1273 \mathrm{~K}$ under flowing air $\left(0.833 \mathrm{~mL} \mathrm{~s}^{-1}\right.$, breathing grade, Airgas) at a ramp rate of $0.167 \mathrm{~K} \mathrm{~s}^{-1}$.

\section{S1.5 Catalysis tests}

All the zeolite samples were first transformed into $\mathrm{H}^{+}$-form before the catalysis tests. The calcined sample was dispersed in $1.0 \mathrm{M}$ aqueous $\mathrm{NH}_{4} \mathrm{NO}_{3}$ solution (weight ratio of zeolite to $\mathrm{NH}_{4} \mathrm{NO}_{3}$ solution $=1: 10$ ) for $3 \mathrm{~h}$ at $353 \mathrm{~K}$. The sample was collected by centrifugation and washed with DI water. The process was repeated three times, then the zeolite sample was dried in a convective oven at $343 \mathrm{~K}$ for $12 \mathrm{~h}$. The zeolite in $\mathrm{NH}_{4}{ }^{+}$-form was treated in air $(1.67 \mathrm{~mL}$ $\mathrm{s}^{-1}$, breathing grade, Airgas) in a furnace by increasing the temperature from ambient to $823 \mathrm{~K}$ at $0.167 \mathrm{~K} \mathrm{~s}^{-1}$ rate and holding at this temperature for $4 \mathrm{~h}$.

The liquid phase catalytic conversion of benzyl alcohol in mesitylene was carried out in a three-necked round bottom flask $(100 \mathrm{~mL})$ equipped with a reflux condenser and heated in 
a temperature controlled oil bath under atmospheric pressure and magnetic stirring (500 rpm stirring speed) conditions. Experimental details and product analyses have been reported in our previous publications ${ }^{4-5}$.

\section{S2. Results and discussion}

\section{S2.1 Effect of TEOS quantity on formation of PMFI in VPP process}

To examine the effect of TEOS quantity on PMFI formation, the mass of TEOS was varied from $0.375 \mathrm{~g}, 0.100 \mathrm{~g}, 0.05 \mathrm{~g}, 0.01 \mathrm{~g}$ and $0.005 \mathrm{~g}$, in the intercalation step. The mass of the M-MFI(P) sample was kept at $0.100 \mathrm{~g}$ for these experiments. The mass ratios of TEOS/M$\operatorname{MFI}(\mathrm{P})$ were calculated to be $3.75,1.00,0.50,0.10$ and 0.05 . Figure $\mathrm{S} 1$ shows the morphology of M-MFI(P) samples after TEOS intercalation. The wetness of the samples decreases with decreasing TEOS/M-MFI(P) ratios. In particular, the sample looked like dry powder when the TEOS/M-MFI(P) ratio was below 0.5 . The Si/Al ratios in Table S2 indicate that nearly all the TEOS was moved into the zeolite to form PMFI except the one TEOS/M-MFI(P) ratio of 3.75. Figures $\mathrm{S} 2$ and $\mathrm{S} 3$ show the XRD patterns and $\mathrm{N}_{2}$ isotherms as well as pore size distribution of these PMFI samples.

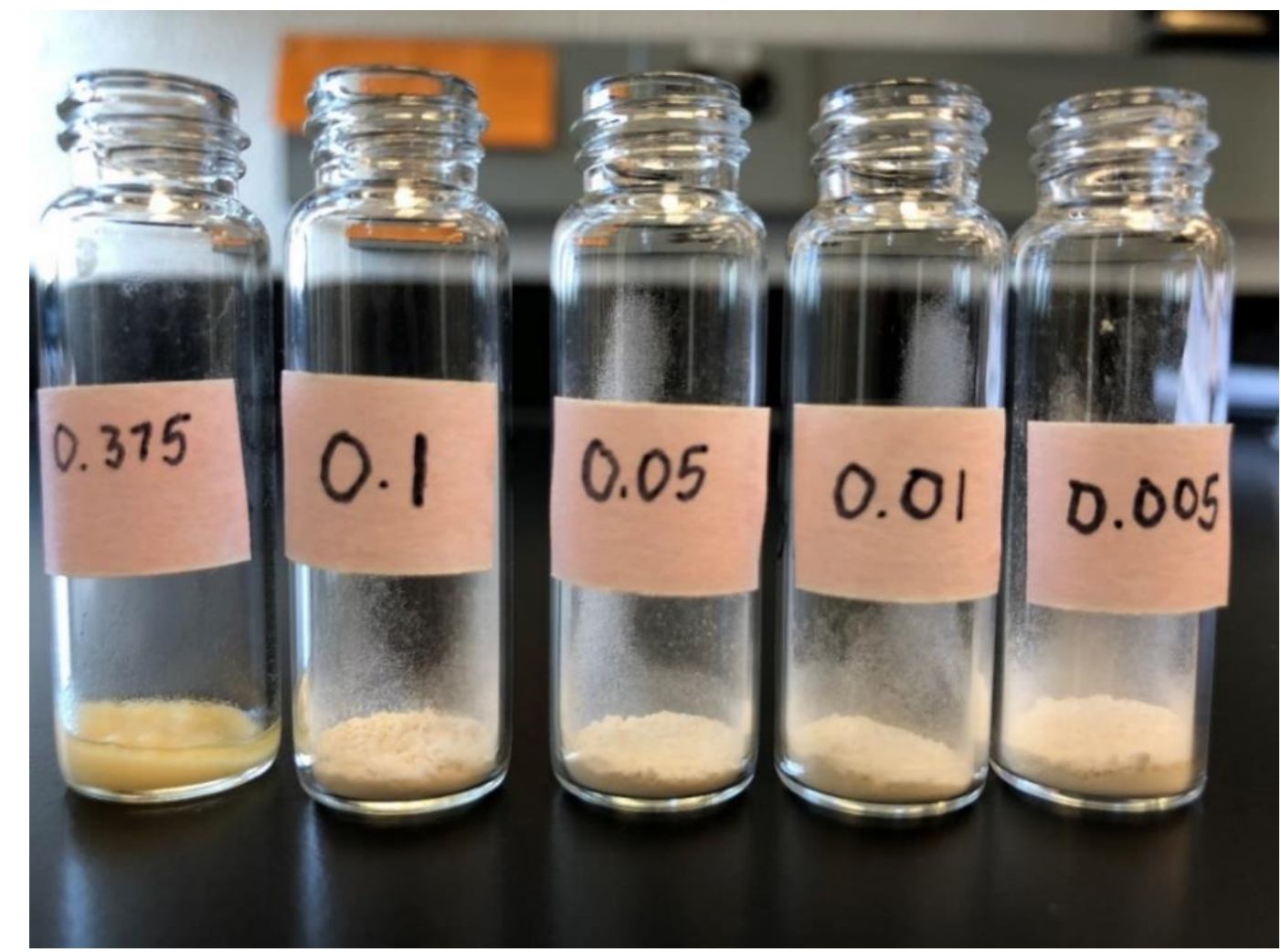

Figure S1. Bulk morphology of M-MFI(P) after TEOS intercalation in the VPP process. The mass ratio of TEOS/M-MFI(P) was controlled to (1) 3.75, (2) 1.00, (3) 0.50, (4) 0.10 and (5) 0.05 , respectively. The numbers in the label of each glass vial is TEOS mass (unit: gram). (synthesis conditions: $343 \mathrm{~K}, \mathrm{M}-\mathrm{MFI}(\mathrm{P})=0.1 \mathrm{~g}$ and mass ratio of $\mathrm{H}_{2} \mathrm{O} / \mathrm{M}-\mathrm{MFI}(\mathrm{P})=10$ in the hydrolysis step) 


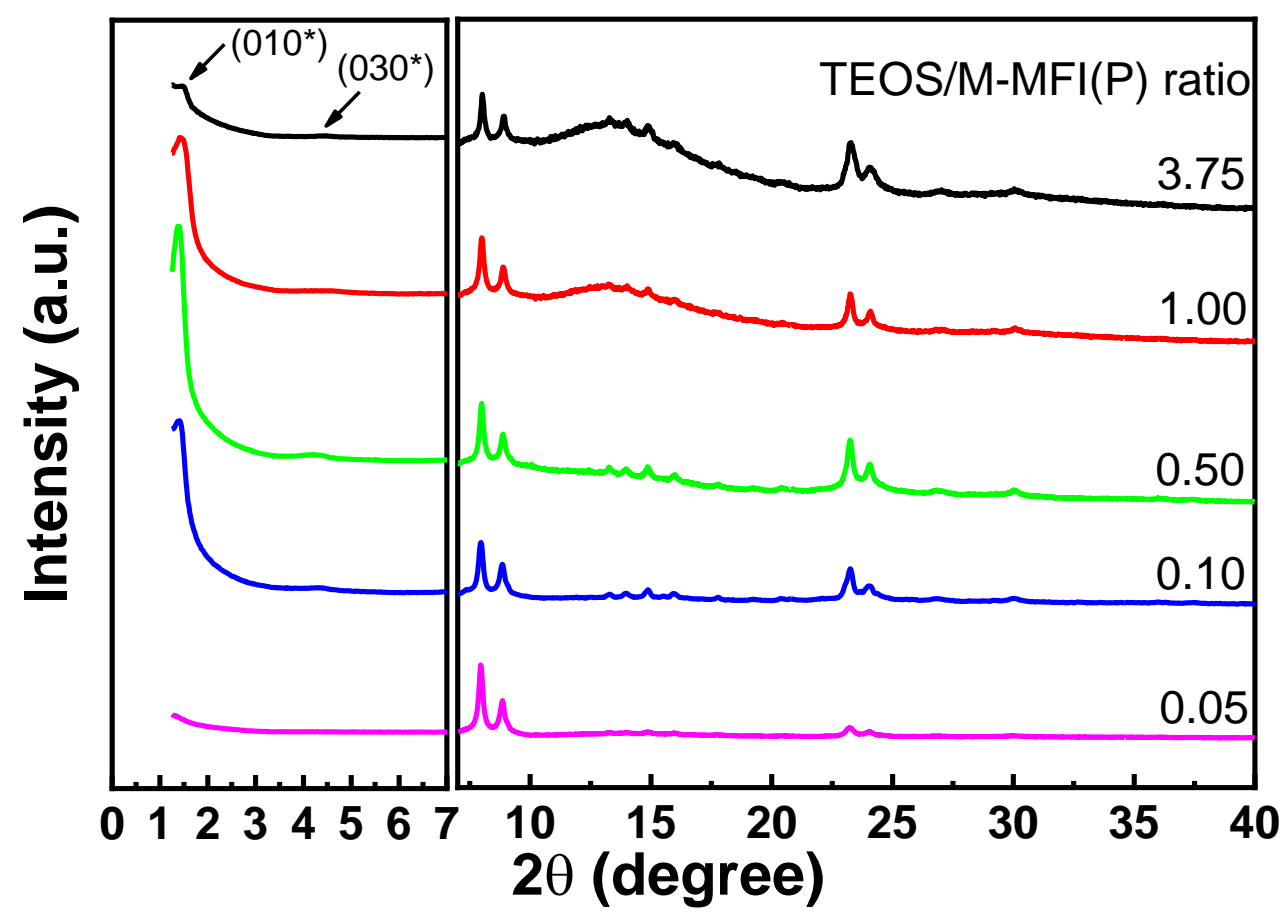

Figure S2. XRD patterns of PMFI synthesized with different TEOS amount (represented by TEOS/M-MFI(P) ratio) added in the TEOS intercalation step in the VPP process.

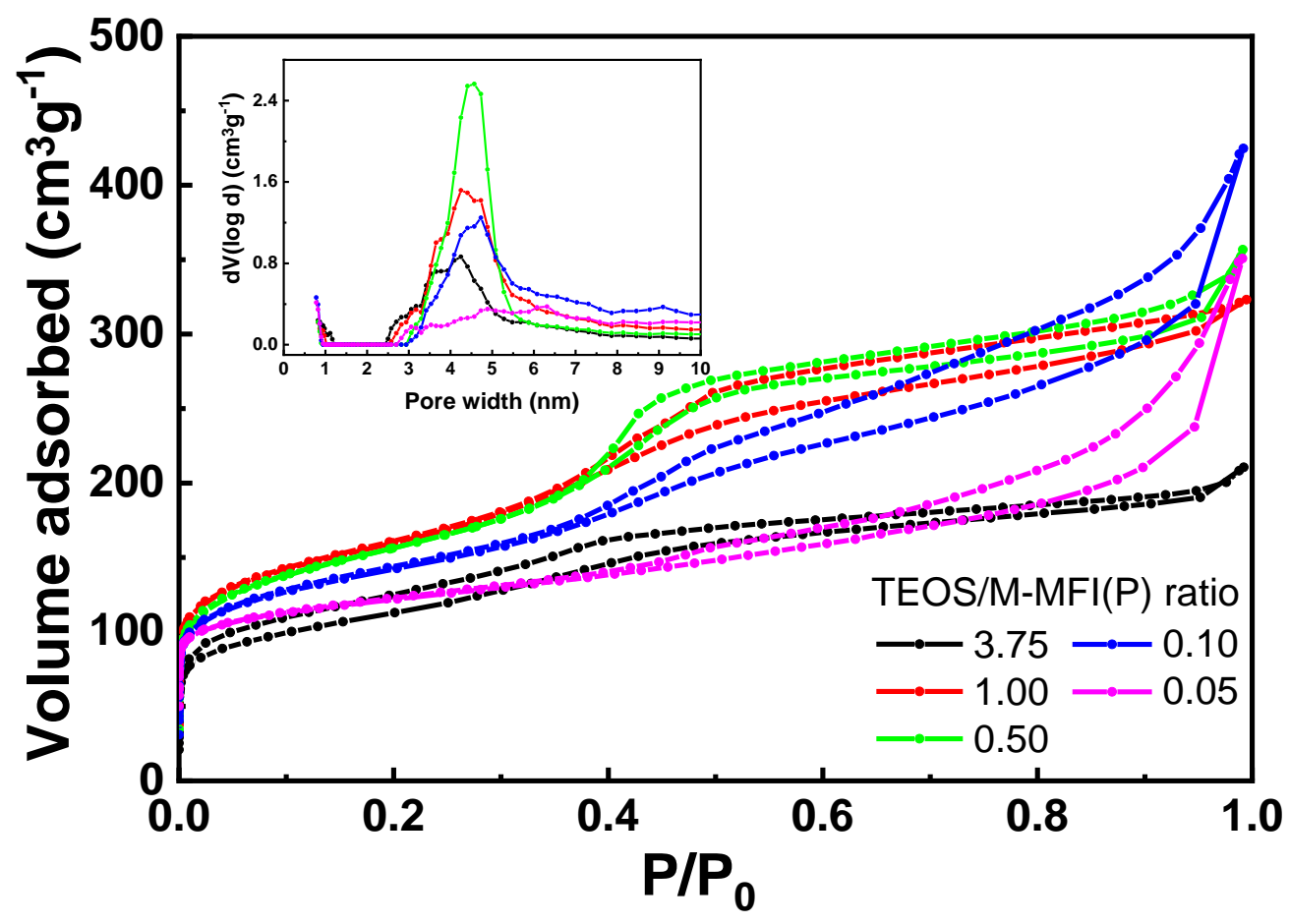

Figure S3. $\mathrm{N}_{2}$ isotherms and NLDFT pore size distributions of PMFI synthesized with different TEOS amount (represented by TEOS/M-MFI(P) ratio) added in the TEOS intercalation step in the VPP process. 
Table S1. Textural properties of PMFI synthesized under different ratio of TEOS/multilamellar MFI.

\begin{tabular}{|c|c|c|c|c|c|c|}
\hline $\begin{array}{c}\text { TEOS/M- } \\
\operatorname{MFI}(\mathrm{P}) \text { ratio }\end{array}$ & $\begin{array}{c}V_{\text {micro }}{ }^{a} \\
{\left[\mathrm{~cm}^{3} \mathrm{~g}^{-1}\right]}\end{array}$ & $\begin{array}{l}\text { S }_{\text {micro }}{ }^{a} \\
{\left[\mathrm{~m}^{2} \mathrm{~g}^{-1}\right]}\end{array}$ & $\begin{array}{c}\mathbf{S}_{\mathbf{e x t}}{ }^{a} \\
{\left[\mathrm{~m}^{2} \mathrm{~g}^{-1}\right]}\end{array}$ & $\begin{array}{c}V_{\text {total }}^{b} \\
{\left[\mathrm{~cm}^{3} \mathrm{~g}^{-1}\right]}\end{array}$ & $\begin{array}{c}V_{\text {meso }}{ }^{c} \\
{\left[\mathrm{~cm}^{3} \mathrm{~g}^{-1}\right]}\end{array}$ & $\begin{array}{c}\text { S }_{\text {Bet }}{ }^{d} \\
{\left[\mathrm{~m}^{2} \mathrm{~g}^{-1}\right]}\end{array}$ \\
\hline 3.75 & 0.012 & 47 & 324 & 0.294 & 0.282 & 371 \\
\hline 1.00 & 0.054 & 87 & 442 & 0.467 & 0.413 & 529 \\
\hline 0.50 & 0.099 & 133 & 484 & 0.526 & 0.430 & 617 \\
\hline 0.10 & 0.106 & 140 & 419 & 0.526 & 0.420 & 559 \\
\hline 0.05 & 0.103 & 245 & 194 & 0.367 & 0.264 & 439 \\
\hline $\mathrm{M}-\mathrm{MFI}^{e}$ & 0.087 & 196 & 253 & 0.371 & 0.284 & 448 \\
\hline
\end{tabular}

${ }^{a}$ Determined from t-plot method; ${ }^{b}$ Determined by non-localized density functional theory (NLDFT) method from adsorption branch of $N_{2}$ isotherm; ${ }^{c} V_{\text {meso }}=V_{t}-V_{\text {micro }}$; ${ }^{d}$ Determined from Brunauer, Emmett, and Teller (BET) method; ${ }^{e}$ Reported in our previous publication ${ }^{2}$.

Table S2. Si and Al compositions of PMFI zeolites synthesized with different TEOS/M-MFI(P) ratios in the VPP process.

\begin{tabular}{|c|c|c|c|c|c|}
\hline \multirow{2}{*}{$\begin{array}{c}\text { PMFI }^{a} \\
\text { (composition) }\end{array}$} & 3.75 & 1.00 & 0.50 & 0.10 & 0.05 \\
\cline { 2 - 6 } & 142 & 74 & 61 & 51 & 50 \\
\hline $\mathrm{Si} / \mathrm{Al} \mathrm{ratio}{ }^{b}$ & 111 & 70 & 61 & 53 & 50 \\
\hline $\mathrm{Si} / \mathrm{Al} \mathrm{ratio}{ }^{c}$ & & \multicolumn{5}{|c|}{ TEOS/M-MFI(P) ratio } \\
\hline
\end{tabular}

${ }^{a}$ All PMFI samples were prepared from M-MFI(P) (Si/Al ratio $\left.=49\right) ;{ }^{b}$ Calculated from Si and Al contents in MMFI(P) and TEOS used in VPP process; ${ }^{b}$ Determined by elemental analysis (ICP-OES).

\section{S2.2 Effect of TEOS intercalation temperature on formation of PMFI in VPP}

To study the influence of TEOS intercalation temperature on formation of PMFI in the VPP process, the temperature was varied from $363 \mathrm{~K}, 383 \mathrm{~K}, 403 \mathrm{~K}$ to $423 \mathrm{~K}$, in sequence. The XRD data in Figure S4 show that all four PMFI samples synthesized at different intercalation temperatures have similar diffraction patterns. The appearance of both wide-angle and lowangle XRD peaks indicate that both MFI crystalline structure and long-range ordering of zeolitic layers are preserved in the VPP process. The PMFI structure does not seem to be dependent on the intercalation temperature in the studied temperature range. The similar $\mathrm{N}_{2}$ uptake and pore size distribution in the isotherm data in Figure S5 further confirm this conclusion. 


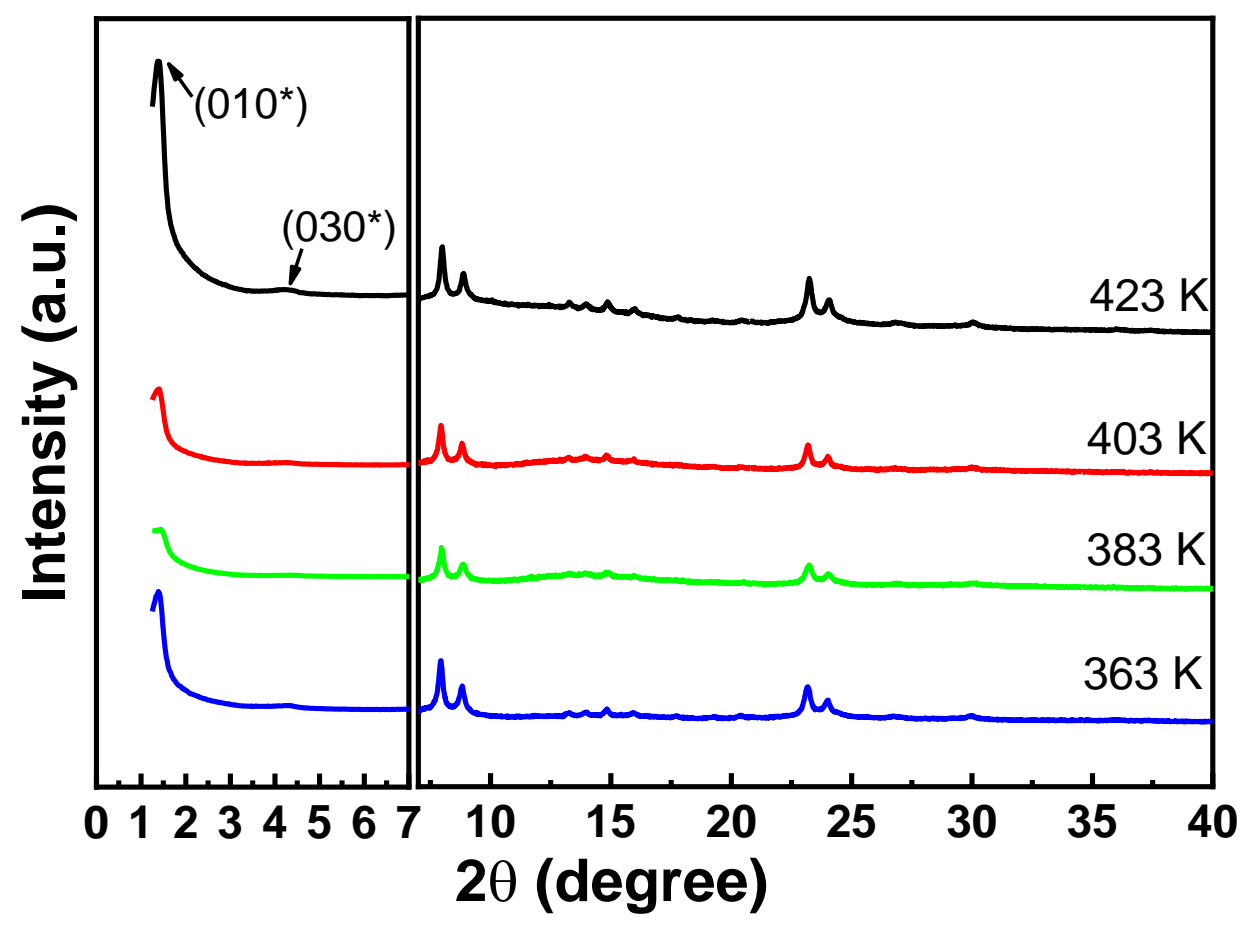

Figure S4. XRD patterns of PMFI synthesized at different TEOS intercalation temperatures in the VPP process.

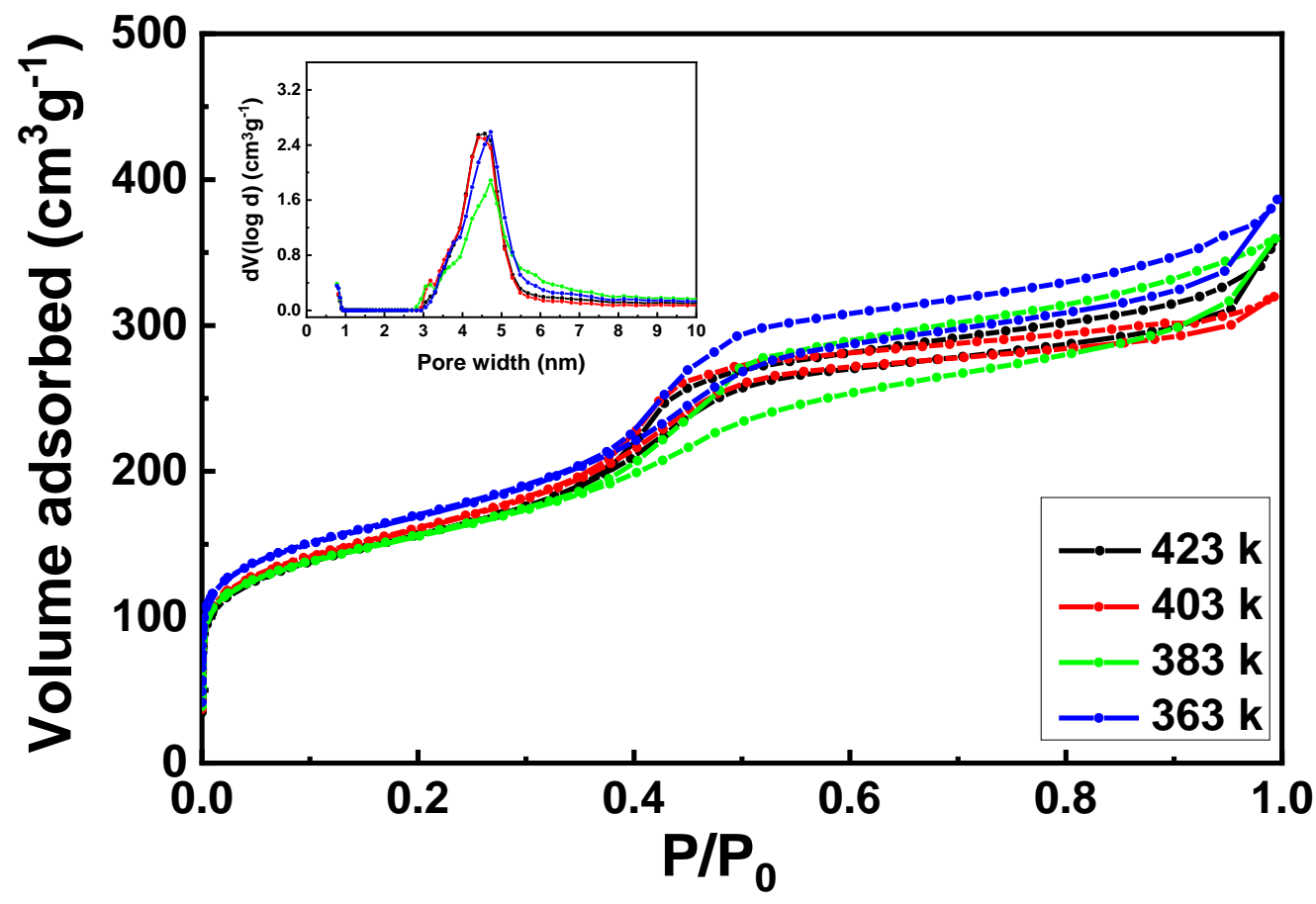

Figure S5. $\mathrm{N}_{2}$ isotherms and NLDFT pore size distributions of PMFI synthesized at different TEOS intercalation temperatures in the VPP process. 


\section{S2.3 Effect of water amount in hydrolysis step on formation of PMFI in VPP}

In the hydrolysis step, water quantity was varied from $0.0 \mathrm{~g}, 0.1 \mathrm{~g}, 0.5 \mathrm{~g}$ and $1.0 \mathrm{~g}$. The rest of the synthesis procedure was the same as that described in Section S1.3. Figures S6 and S7 confirm that water does not influence the crystallinity and textural properties of the synthesized PMFI zeolite significantly, since all four samples had similar XRD patterns and $\mathrm{N}_{2}$ isotherms.

Water content in M-MFI(P) was quantified byTGA measurement. As shown in Figure $\mathrm{S} 8$, the $\mathrm{C}_{22-6-6}$ template started to lose weight at $483 \mathrm{~K}$, and the decomposition was completed at $\sim 900 \mathrm{~K}$. The initial weight loss should be due to water desorption, and the final weight loss was caused by $\mathrm{C}_{22-6-6}$ combustion. According to TGA data of $\mathrm{C}_{22-6-6}$, the first weight loss $(<563$ $\mathrm{K})$ in $\mathrm{M}-\mathrm{MFI}(\mathrm{P})$ was attributed to the removal of adsorbed water. The higher weight loss in $\mathrm{M}$ $\operatorname{MFI}(\mathrm{P})$ (dried in convective oven) than $\mathrm{M}-\mathrm{MFI}(\mathrm{P})$ (dried by vacuum oven) at this temperature range indicates higher water content in the former sample. The calculation shows that $\sim 16 \mathrm{wt} \%$ $\mathrm{H}_{2} \mathrm{O}$ adsorbed in M-MFI(P) dried regularly in the convective oven. After vacuum drying, the remaining water in $\mathrm{M}-\mathrm{MFI}(\mathrm{P})$ was $\sim 12 \mathrm{wt} \%$.

The following calculation shows the correlation between water adsorbed in M-MFI(P) and TEOS hydrolysis. For $0.1 \mathrm{~g} \mathrm{M}-\mathrm{MFI}(\mathrm{P})$, the adsorbed water in zeolite is $0.1 \mathrm{~g} \mathrm{x} 16 \mathrm{wt} \%=$ $0.016 \mathrm{~g}$, equivalent to $8.88 \times 10^{-4} \mathrm{~mol} \mathrm{H}_{2} \mathrm{O}$. According to the reaction stoichiometry, $4 \mathrm{H}_{2} \mathrm{O}+$ $1 \mathrm{Si}\left(\mathrm{OC}_{2} \mathrm{H}_{6}\right)_{4} \rightarrow \mathrm{Si}(\mathrm{OH})_{4}+4 \mathrm{C}_{2} \mathrm{H}_{6} \mathrm{OH}, 3.55 \times 10^{-3}$ mol TEOS can be hydrolyzed, equivalent to $\sim 0.05 \mathrm{~g}$ TEOS amount. Therefore, water adsorbed in M-MFI(P) zeolite is sufficient for hydrolysis of TEOS used in PMFI synthesis with TEOS/M-MFI(P) $<0.5$. This is consistent with our experiment results that PMFI could be successfully synthesized with zero water addition in the hydrolysis step. For comparison, the M-MFI(P) sample was dried in a vacuum oven at $393 \mathrm{~K}$ for $12 \mathrm{~h}$, and the pillaring structure in PFMI did not form, as shown by the absence of clear low-angle XRD peaks in Figure S9.

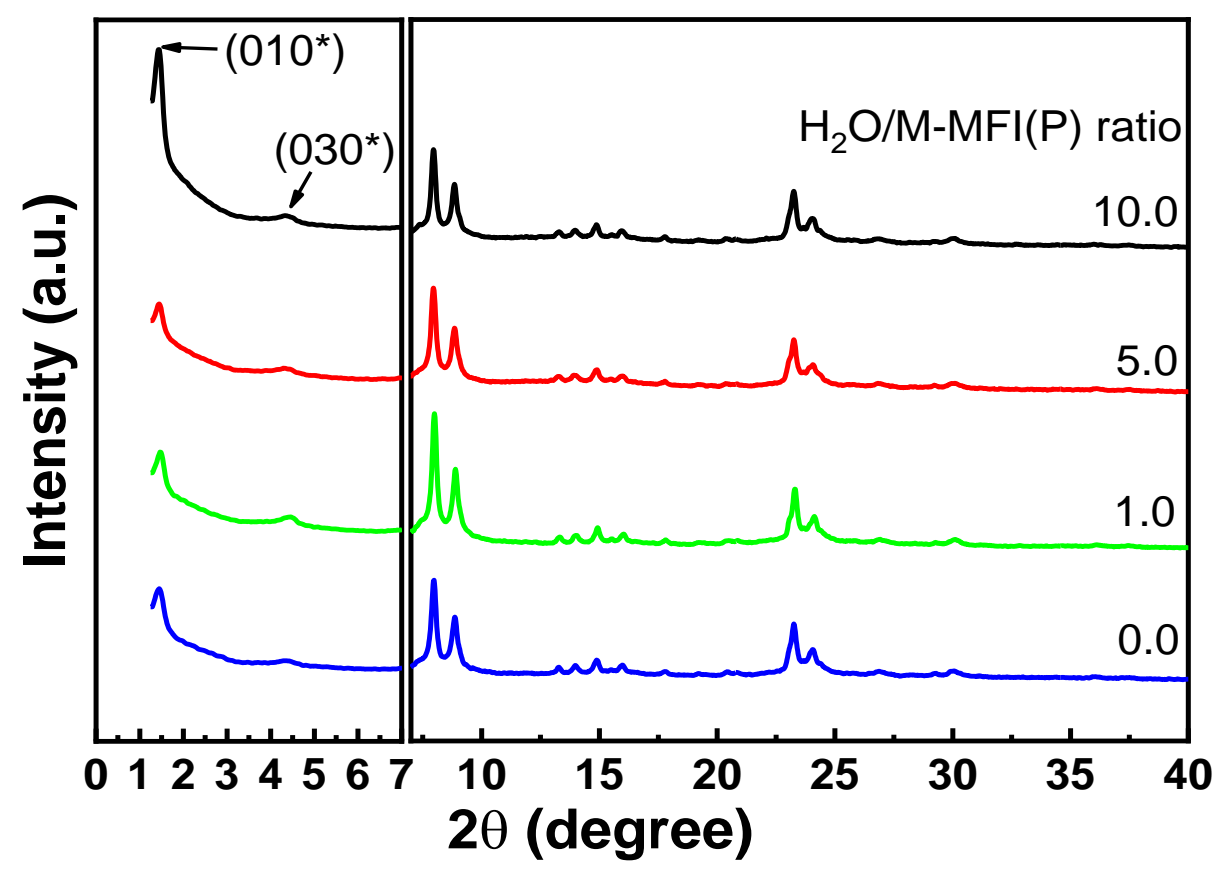

Figure S6. XRD patterns of PMFI synthesized with different water amount (represented by $\mathrm{H}_{2} \mathrm{O} / \mathrm{M}-\mathrm{MFI}(\mathrm{P})$ ratio) loaded in the TEOS hydrolysis step in the VPP process. 


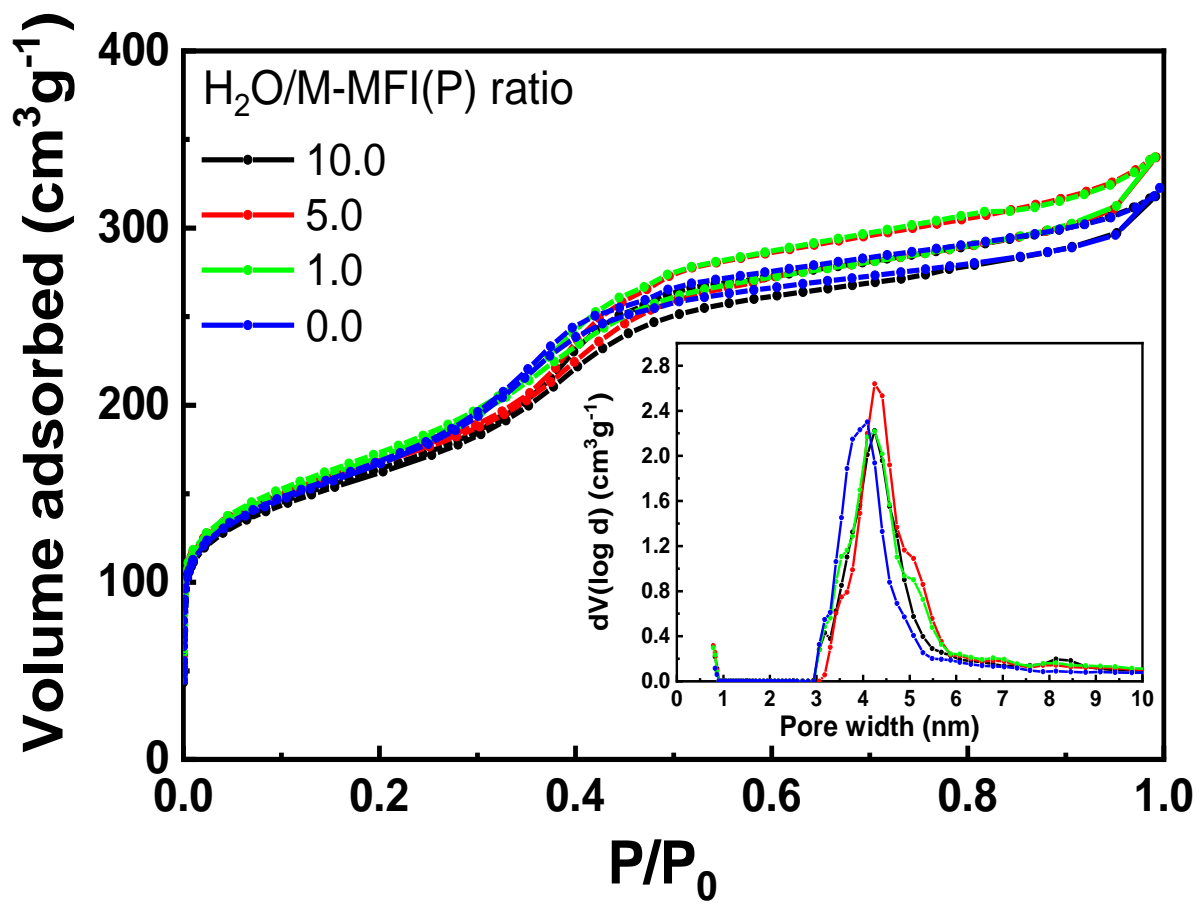

Figure S7. $\mathrm{N}_{2}$ isotherms and NLDFT pore size distributions of PMFI synthesized with different water amount (represented by $\mathrm{H}_{2} \mathrm{O} / \mathrm{M}-\mathrm{MFI}(\mathrm{P})$ ratio) loaded in the TEOS hydrolysis step in the VPP process.

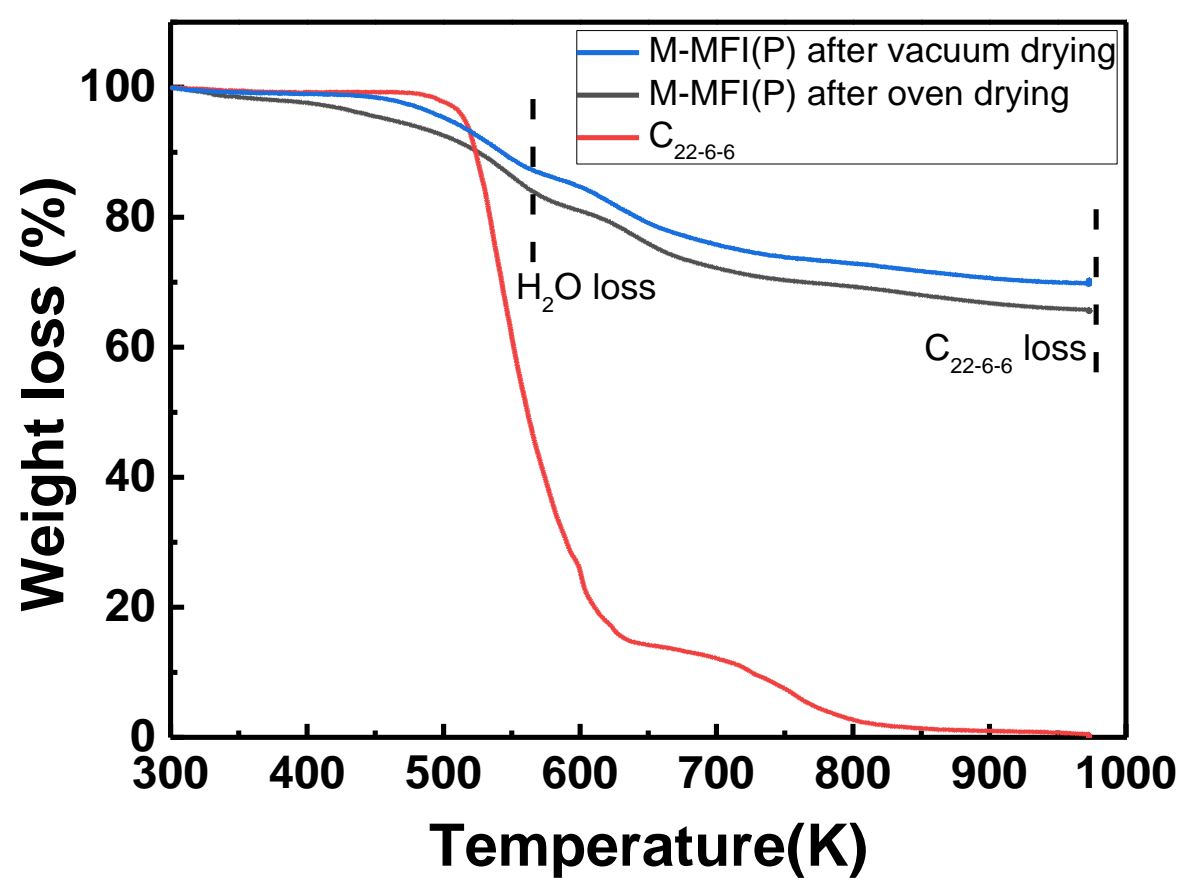

Figure S8. TGA of M-MFI(P) dried in a convective oven at $343 \mathrm{~K}$ for $12 \mathrm{~h}$ and with M-MFI(P) pre-dried at $393 \mathrm{~K}$ for $12 \mathrm{~h}$ in vacuum oven, respectively. $\mathrm{C}_{22-6-6}$ template used in M-MFI(P) synthesis was included for comparison. 


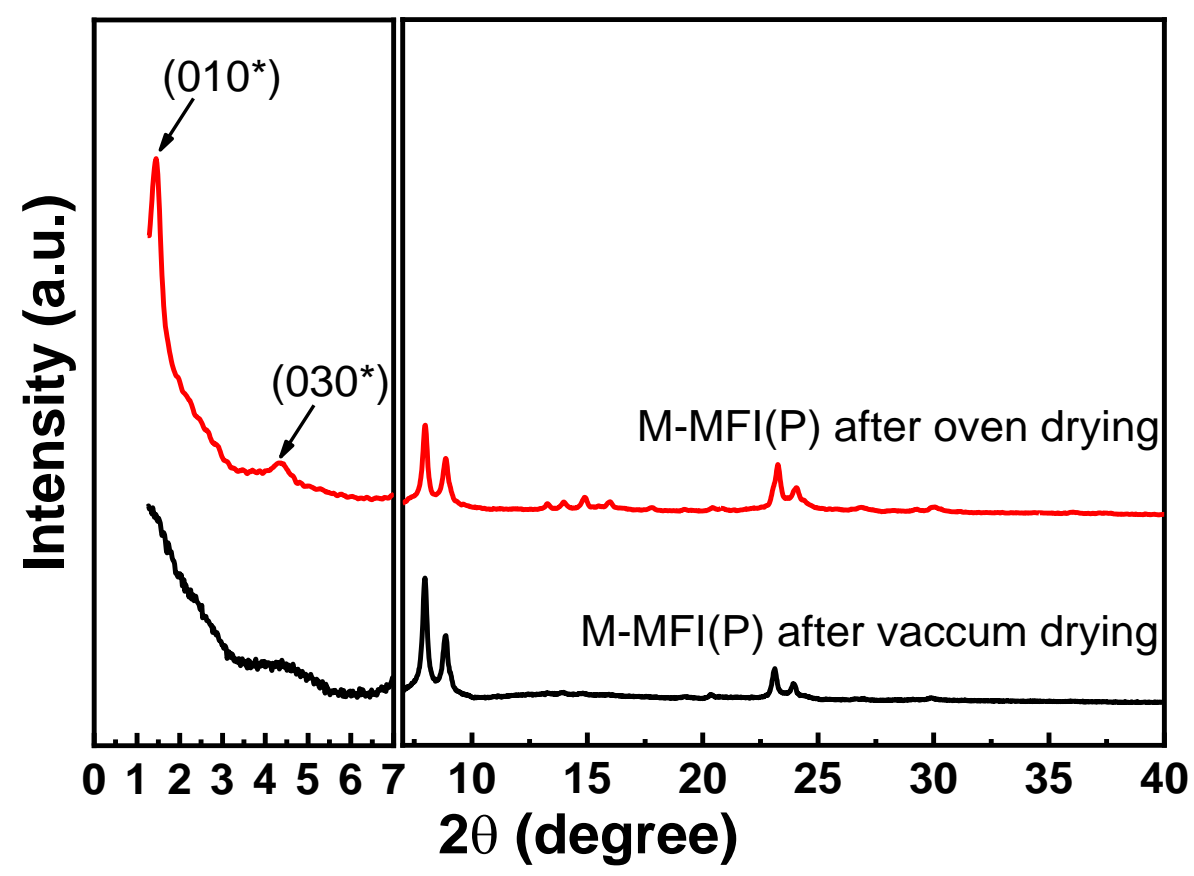

Figure S9. XRD patterns of PMFI zeolites prepared in VPP process with M-MFI(P) dried in a convective oven at $343 \mathrm{~K}$ for $12 \mathrm{~h}$ and with $\mathrm{M}-\mathrm{MFI}(\mathrm{P})$ pre-dried in vacuum oven at $393 \mathrm{~K}$ for $12 \mathrm{~h}$, respectively, before TEOS intercalation.

S2.4 Characterization of PMFI prepared by one-unit under one-time VPP operation

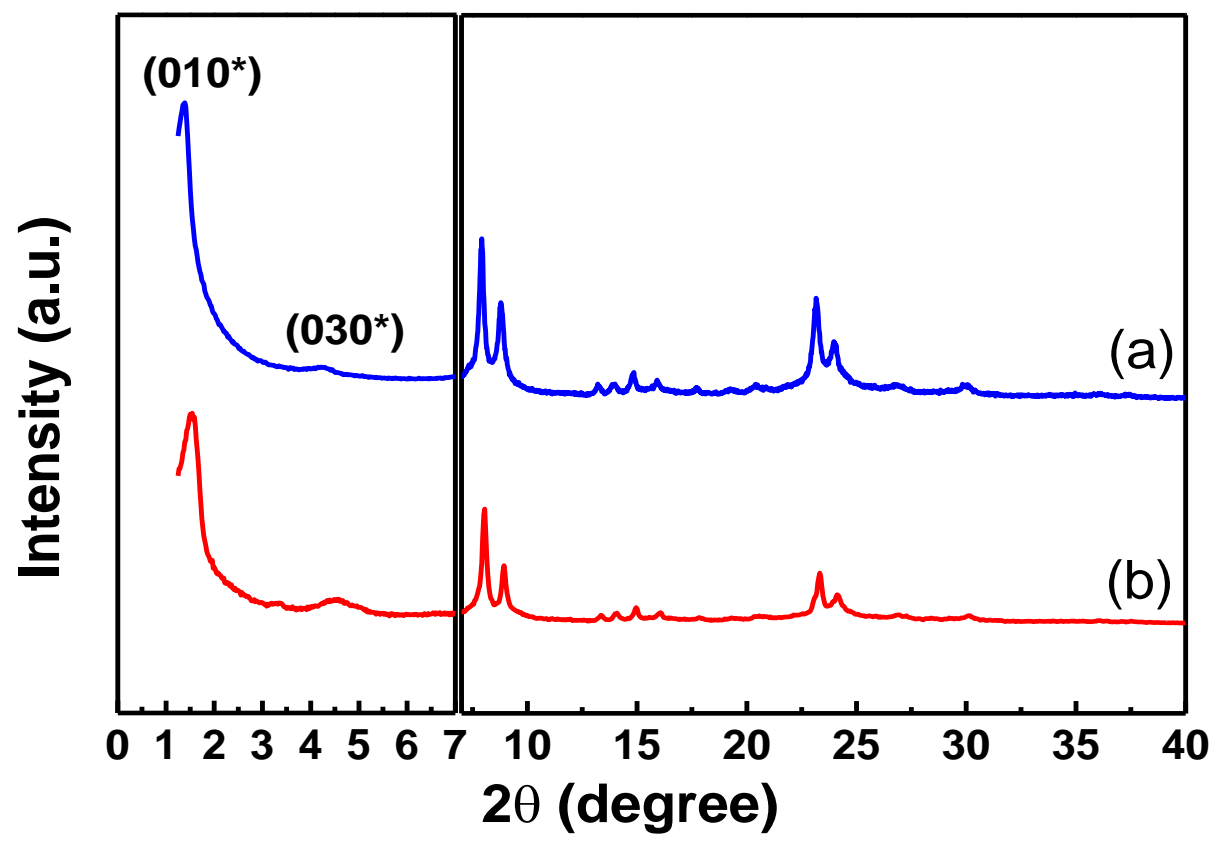

Figure S10. XRD data of PMFI prepared by the VPP process using (a) the multiple-step operation (scheme shown in Figure 1) and (b) one-unit under one-time operation (scheme shown in Figure 3), respectively. 


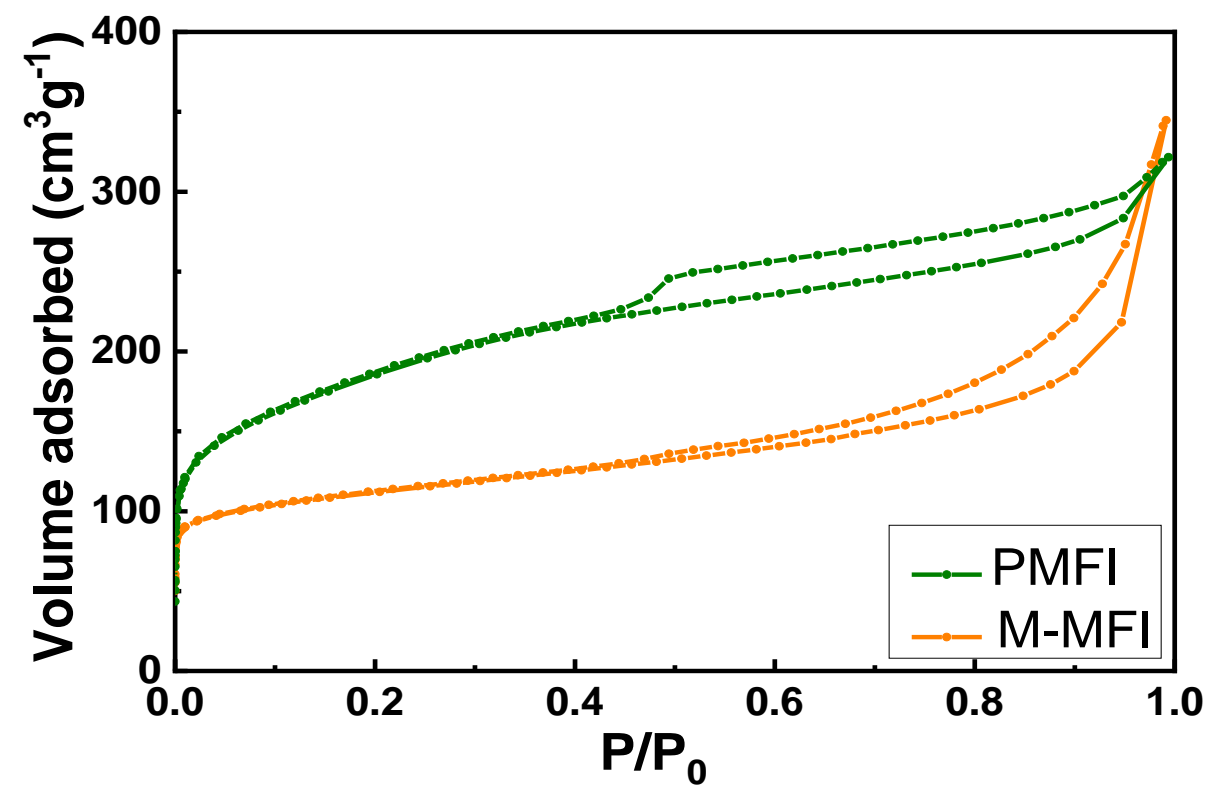

Figure S11. $\mathrm{N}_{2}$ isotherm of PMFI prepared by the VPP process using the one-unit under onetime operation (scheme shown in Figure 3). The $\mathrm{N}_{2}$ isotherm of M-MFI was represented here for comparison purpose.

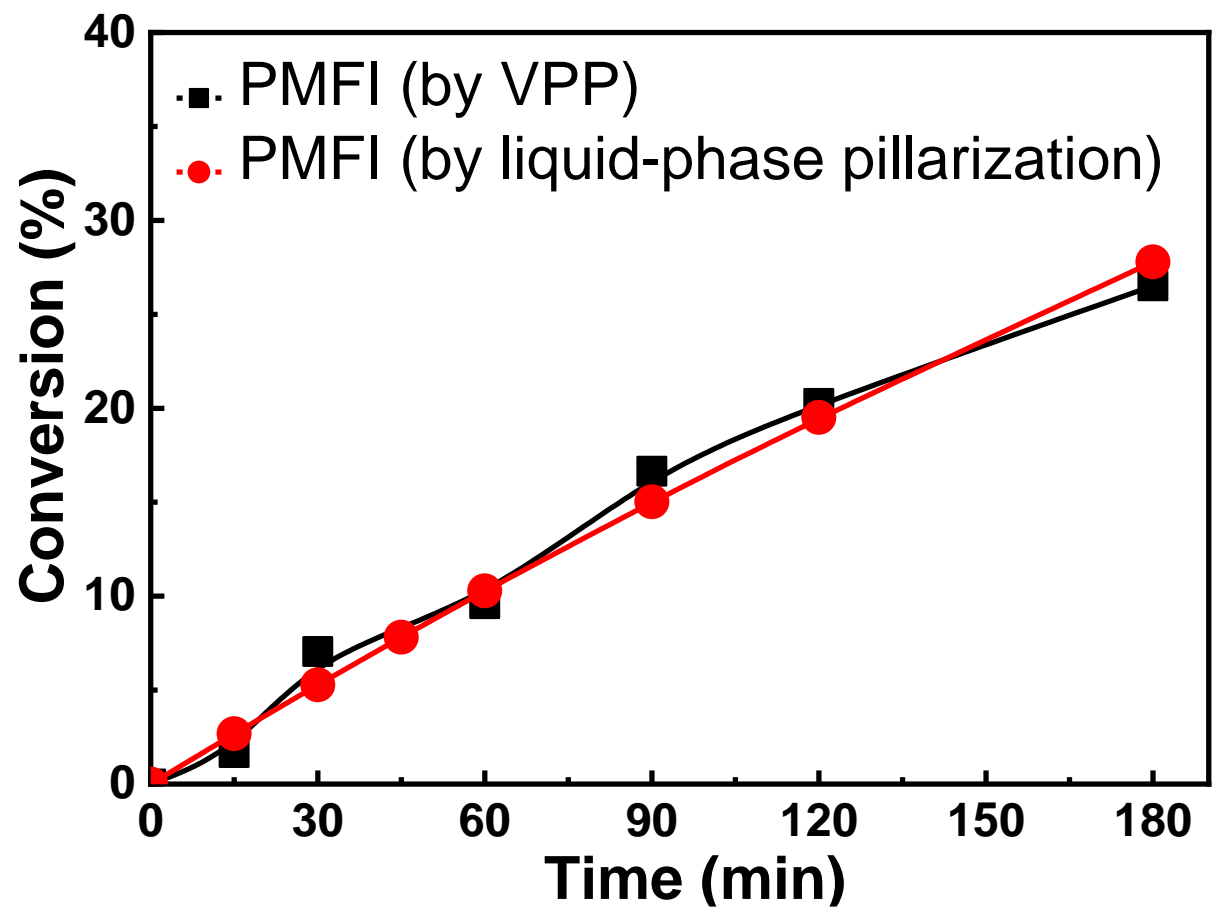

Figure S12. Benzyl alcohol conversion in mesitylene over PMFI samples prepared by both the VPP and the conventional liquid-phase pillarization, respectively. (Reaction condition: $348 \mathrm{~K}$, 0.075 g catalyst, 500 rpm stirring speed.) 


\section{References}

1. Choi, M.; Na, K.; Kim, J.; Sakamoto, Y.; Terasaki, O.; Ryoo, R. Stable single-unit-cell nanosheets of zeolite MFI as active and long-lived catalysts. Nature 2009, 461, 246.

2. Emdadi, L.; Wu, Y.; Zhu, G.; Chang, C. C.; Wei, F.; Pham, T.; Lobo, R, F.; Liu, D. Dual template synthesis of meso- and microporous mfi zeolite nanosheet assemblies with tailored activity in catalytic reactions. Chem. Mater. 2012, 26, 1345.

3. Liu, D.; Bhan, A.; Tsapatsis, M.; Hashimi, S. A. Catalytic Behavior of Brønsted Acid Sites in MWW and MFI Zeolites with Dual Meso- and Microporosity. ACS. Catal. 2011, 1, 7.

4. Zhang, X.; Liu, D.; Xu, D. Asahina, S.; Cychosz, K. A.; Agrawal, K. V. Synthesis of selfpillared zeolite nanosheets by repetitive branching. Science 2012, 29, 1684.

5. Liu, D.; Zhang, X.; Bhan, A.; Tsapatsis, M. Activity and selectivity differences of external Brønsted acid sites of single-unit-cell thick and conventional MFI and MWW zeolites. Micropor. Mesopor. Mater. 2014, 200, 287. 